\title{
10 The next step for the cultural-developmental approach: from moral reasoning to moral intentions and behavior
}

\section{Gisela Trommsdorff}

The main goal of this volume is to present a cultural-developmental approach to moral psychology. The volume addresses the divergent and multiple ways that morality develops in diverse cultures, thus synthesizing developmental and cultural perspectives. It draws attention to the question of how to bridge the lenses of developmental and cultural psychology. The authors expand current theoretical approaches by including conceptualizations of morality beyond Western traditions and highlighting more than one kind of moral reasoning. The goal of this volume is to lay the groundwork for a theoretical approach to moral development that is valid both across and within cultures.

\section{Overview of the volume}

Little is known about the development of moral reasoning across the life course in diverse cultures. This volume includes contributions by scholars from a variety of countries who present findings on diverse contexts of moral development. The volume, however, avoids the problem of presenting heterogeneous theoretical approaches. All contributions share the cultural-developmental approach to moral reasoning, and, more specifically, they share Jensen's $(2008,2011$, 2015, and Chapter 1, this volume) assumptions of the template model.

Jensen conceptualizes moral development based on a cultural-developmental template describing developmental patterns of moral reasoning across the life course in terms of three Ethics of Autonomy, Community, and Divinity. The idea of the template model is that the general developmental patterns for the ethics emerge somewhat differently in different cultural contexts and vary on how prominent they become in the course of development in different cultures. For example, the model predicts a peak in the development of Ethic of Autonomy reasoning among American emerging adults. The model also predicts early and prominent development of Ethic of Community reasoning in collectivistic

This chapter is related to the project "Development of Intentionality" ( $\operatorname{Tr} 169 / 14-3)$ as part of the Research Group Limits of Intentionality, University of Konstanz, supported by the German National Research Council (DFG). 
cultures and low levels of development of Ethic of Divinity in individualistic, religiously liberal Western contexts.

This cultural-developmental theoretical model that unifies the volume is also useful because the authors come from diverse disciplines, including anthropology, social psychology, and developmental psychology. Furthermore, the authors make use of different research approaches, including highly diverse samples and diverse qualitative and quantitative measurement techniques for collecting data. While there is theoretical unity across the chapters, the heterogeneity of disciplines and research samples and assessment techniques also allow for promising challenges, modifications, and expansions of the underlying theoretical model. In all, this allows for the advancement of culturaldevelopmental research on morality.

The volume consists of a foreword by Richard Shweder, eight chapters, and two commentaries. The first, introductory chapter by Jensen (Chapter 1, this volume) presents a theoretical overview, explains the main ideas of the template model, and provides integration of key findings from the chapters in the volume. The cultural side of the present theoretical approach goes back to Richard Shweder, who has challenged Western theorizing on religion and morality (Shweder, Much, Mahapatra, et al., 1997). The next seven chapters present data from diverse cultures and developmental periods. Most chapters include samples that differ on religiosity, thus highlighting the complex role of religion in moral reasoning.

Specifically, two chapters include religious samples from the United States (religiously conservative emerging adults in Padilla-Walker \& Nelson, Chapter 5, this volume; religiously liberal and conservative children, adolescents, and adults in Jensen, Chapter 8, this volume). One chapter compares nonreligious and religious Finnish adolescents (Vainio, Chapter 3, this volume). Two chapters examine developmental patterns among Indian samples, focusing on children (Pandya \& Bhangaokar, Chapter 2, this volume) and on adolescents and adults (Kapadia \& Bhangaokar, Chapter 4, this volume). One chapter investigates the moral codes of emerging adults in five countries (Guerra \& Giner-Sorolla, Chapter 6, this volume). Finally, Hickman and DiBianca Fasoli (Chapter 7, this volume) draw on culturally relevant moral vignettes for their discourse analyses among American Evangelical Christian families and Hmong families in both Thailand and the United States. The Appendices to the volume include three questionnaires and a coding manual used by the authors of this volume for their empirical studies on moral reasoning.

As a whole, then, the volume entails a novel theoretical approach to moral reasoning by pointing to the phenomenon of multiple ethics in culture and development. It also provides tools to study moral development in future research. The individual chapters offer specific and original contributions to the general topic of moral development on the basis of the cultural-developmental template. 
Most chapters study developmental patterns of moral reasoning in terms of the three Ethics of Autonomy, Community, and Divinity, in line with the editor's theoretical starting point. Furthermore, the chapters focus on development in cultural context, discussing cultural specificities as well as universalities. With respect to the concept of culture, most chapters also address religiosity as a component of culture and a major factor in moral development.

In sum, the diverse methods and samples of the volume may seem a limitation at first sight, but in my view turn out to be a strength. The great advantage of this otherwise heterogeneous volume is that the chapters are organized around the template model approach. This theoretical frame is appealing, and the chapters represent a significant theoretical improvement to moral psychology by enabling the study of more than one kind of moral reasoning through the inclusion of culture and religion (e.g., Shweder, 1990). Thereby, the volume also builds on progress achieved in the study of moral development by cultural scholars (Miller, Bersoff, \& Harwood, 1990).

There is some repetition across chapters (the definitions of the three ethics), but the meaning of major concepts (culture, religiosity, moral reasoning, moral code) is also developed somewhat differently in different chapters. Many of the chapters address hypothetical dilemmas, whereas predictions of moral behavior is the focus of but one chapter. Also, the cross-sectional data of most chapters limit the discussion of developmental issues. I also think that future theoretical and empirical work would profit from taking into account alternative research on culture, religion, and morality in individual development. However, the major strength of this volume is that it opens the door for a new and promising cultural-developmental approach to moral psychology, thus contributing to the science of moral development in a global world.

In the following, I therefore first focus on moral intentions and behavior, conceiving of moral development as an aspect of agency. Self-regulation, an indicator of intentionality, is viewed here as an important aspect for the development of moral behavior. Second, I address moral agency and behavior as related to self- and worldviews. I discuss Jensen's approach of the three ethics in relation to cultural differences in self- and worldviews, focusing on the value of autonomy and relatedness underlying different approaches to moral behavior in terms of cultural fit.

\section{From moral reasoning to moral intentions and behavior}

\section{Moral behavior as agency}

In the following, I conceptualize moral development as an aspect of agency that aims to achieve a fit between the self and the world in line with moral 
standards or rules of the community. This view allows for an extension of the study of moral development to moral behavior. Moral behavior (e.g., helping, cooperation) is based on agency and goes beyond cognitive and motivational processes of moral reasoning. Basic preconditions for the development of moral behavior are intentionality (Tomasello, 1999) and self-regulation (including behavior and emotion regulation; Trommsdorff, 2015).

The question for the development of moral behavior is how a fit between the self and the world can be achieved in such a way that culturally valid and internalized moral standards of the community are met. Once the individual develops the goal to achieve this fit, this fuels the motivation to organize the goal-directed behavior in line with moral standards. Elements of this moral motivation are expectations of successful goal achievement (e.g., due to selfefficacy beliefs), which promote agency in moral behavior. Other elements of this moral motivation are self-regulatory processes. The development of self-regulation implies behavioral regulation (e.g., executive control) and the regulation of internal mental processes (control of emotions, motivation, cognitions; for an overview, see Heikamp, Trommsdorff, \& Fäsche, 2013; Karoly, 1993). So far, little is known about the developmental processes of agency and intentionality in moral behavior. Even less is known about the impact of cultural factors on the development of agency and intentionality (including motivation and self-regulation) in moral behavior (Trommsdorff, in press).

In their culture-informed research on moral psychology, Miller, Bersoff, and Harwood (1990) have pointed to the role of agency in moral behavior. There is room for individual interpretation and decision making (depending on the person and the situation) even in cases of moral obligations and regulations. Duty-based moral behavior may focus on conformity or on caring, as a recent study on the influence of cultural values has shown (Becker, Vignoles, Owe, et al., 2014).

A child develops a self-view and a worldview and related values and rules for moral behavior that are dependent on the cultural context. Worldviews are subjective and focus on the material (social, physical, and natural) and the nonmaterial and supernatural ("other") world where religious beliefs and spiritual experiences become relevant (Trommsdorff, 2015). Depending on whether the material and nonmaterial worlds are seen as fixed or malleable, different control beliefs (Rothbaum \& Wang, 2011) and related qualities of agency are activated by adapting to the given circumstances ("secondary control") or by changing the situation according to one's own goals ("primary control"). Self- and worldviews are fueled by cultural values, and they influence moral standards and enter into religious and moral intentions (Trommsdorff, 2015).

Cultural values inform the development of self- and worldviews and the respective moral standards and "systems" of meaning (Molden \& Dweck, 2006). Moral standards influence goal setting and motivate behavior. Cultural 
values thus function as motivational orientations that underlie self- and worldviews. For example, cultural values prioritizing an independent self are related to moral standards of autonomy, focusing on the individual internal characteristics, whereas cultural values prioritizing an interdependent self are related to moral standards of community, focusing on situational (social) factors. In some cultural contexts, moral standards and rules are clearly defined, they have a specific meaning, and they are related to specific behavior; in other contexts, moral standards and rules have to be interpreted, they may be negotiated, and they can vary among different contexts. For example, children's prosocial behavior varies according to their cultural background (European American, Asian) and their interpretation of the situation: is the child's prosocial intervention helpful or undesirable (losing face) for a stranger who needs help (Trommsdorff, Friedlmeier, \& Mayer, 2007)? This implies that nonoccurrence of prosocial intervention may be motivated by empathic concern. This also implies agency when deciding between intervention and inhibition (or promotion and avoidance goals). Further, during individual development the definition and options for moral behavior change depending on sociocultural expectations and implicit developmental theories of the socializing agents. During the life course, moral rules change as a result of developmental tasks or sociocultural changes. Furthermore, in a changing society, old and new values may conflict in decision making and moral behavior. Immigrants often experience such conflicting moral rules during acculturation processes. In general, in the present globalized world, individuals face the developmental task to coconstruct moral guidelines and organize their moral behavior accordingly. Jensen's template model of the three ethics becomes relevant again.

For example, in several East Asian cultures (such as Japan), the young child is perceived as being directly related to God or the Other World. The moral imperative is that parents refrain from negative sanctions of the young child's lack of conformity to rules. Instead, the child learns to distinguish "good" from "bad" and to identify moral behavior through observation or guided participation in everyday practices. Thereby, the child develops a selfconstrual influenced by cultural values and moral orientations, and, further, moral behavior develops in a way that fits the sociocultural self.

The contexts and the respective options for moral behavior are to a certain degree actively selected by the individual. For example, moral behavior may imply choosing between "Self's Interest" and "Other's Interest" (see the standard coding manual for the three ethics in Appendix A). However, such intentional, goal-oriented, agentic moral development is limited by biological and sociocultural boundaries. Therefore, research on agency in moral development has implications for the study of agency and intentionality in a culturaldevelopmental framework (Trommsdorff, 2012b). 
To summarize, so far, Jensen's model of the three ethics has been largely tested for moral reasoning. When testing the relation between moral reasoning and moral behavior in future research, the role of agentic self-regulation in cultural context will be of major concern. The development of both moral reasoning and moral behavior is guided by cultural values and culture-informed moral standards and may be studied according to Jensen's template framework of the three ethics. Research on the development of moral behavior should take into account agency and therefore focus on intentionality, decision making, and self-regulation processes. The cultural context influencing the child's socialization and the development of the child's intentionality conveys cultural values, related moral standards, and moral reasoning, thus influencing the child's development of moral agency, including moral motivation, emotions, and moral behavior.

\section{Development of self-regulation}

One aspect of moral agency and intentionality is the development of selfregulation, especially behavioral (such as delay of rewards, focus of attention, impulse control) and emotion regulation (such as modulating the experience and expression of positive and negative emotions; Trommsdorff, 2009). Selfregulation is motivated to reach goals in the face of difficulties and over time. Self-regulation is shaped by cultural models of independence or interdependence and is related to self- and worldviews (e.g., people's entity or incremental theories in stability or malleability of self; Dweck, 2000; Molden \& Dweck, 2006), control beliefs (e.g., primary, secondary, harmony control; Morling \& Evered, 2006; Weisz, Rothbaum, \& Blackburn, 1982), and the preference for approach/promotion- or avoidance/prevention-focused goals (Higgins, 2012). Self-regulation guides culturally adaptive behavior in development (Trommsdorff, 2009, 2012b, 2015; in press). On the one hand, self-regulation results from the internalization of rules in line with the expectations and goals of socializing agents. Thereby, it is relevant for moral judgment. On the other hand, self-regulation is relevant for pursuing culturally valued goals and for the construction of a moral identity based on the internalization of moral values and norms.

Successful internalization is influenced by the quality of the parent-child relationship (Grusec \& Goodnow, 1994). Kochanska, Coy, and Murray (2001) view "committed compliance" as an early precursor of moral internalization, strongly related to the internalization of parental rules and values, whereas "situational compliance" is mostly sustained by parental control depending on external factors. Since parenting, including beliefs, goals, and behavior, is influenced by the cultural context (Rothbaum \& Trommsdorff, 2007), the goals for moral behavior (indicated by parental rules) should largely be consistent 
with cultural values guiding the children's moral goals. Here, self-regulation and willpower are necessary, that is, postponing desired rewards to a later time (delay of gratification; Mischel, 1996), inhibiting aggressive behavior, and using effortful control of one's impulses. Agentic self-regulation in the development of morality therefore serves to pursue internalized culturally valued moral goals.

\section{Moral agency as related to self- and worldviews}

Broadly conceptualized, the moral goals for moral behavior may focus on "changing the self," that is, changing one's motives, needs, and emotions, or the focus may be on "changing the world," that is, influencing other persons, animals, or objects. For both kinds of goals, agentic self-regulation is needed. However, depending on culture, different aspects of intentionality and agency are activated (Trommsdorff, 2007, 2009).

\section{Three ethics and moral agency}

In relation to cultural tasks, cultural models of self, and individual development, the broad question guiding moral development is whether primarily to change the world ("primary control") or change the self ("secondary control") (Rothbaum \& Wang, 2011). An individual's preference is part of that person's self-view and worldview: is the self or the world seen as malleable? For example, the Ethic of Autonomy may be related to achieving independence and self-reliance by primary control. The Ethic of Community may be related to achieving interdependence by secondary control; thus, changing oneself serves the goal of maintaining interpersonal harmony in one's social group. However, whether the Ethic of Divinity is related to either primary or secondary control depends on various factors, such as whether the divine order focuses on disciplining nonbelievers or on regulating individual desires and needs or on accepting fate control. Here, basic differences in religious orientations may impact moral motivation and related behavior.

Thus, the development of morality is interrelated with a specific self- and worldview and depends on the normative value priorities and the socialization experiences of children and adolescents (Trommsdorff, 2012a). The self- and worldview give "meaning" (Molden \& Dweck, 2006) to moral values and to related agentic self-regulation. However, moral values are not necessarily distinct and exclusive. For example, both the Ethics of Autonomy and Community can be socialized within cultures and can coexist within individuals. Depending on the situation (e.g., private or public sphere) and the developmental stage, the use of either ethic may differ, as several of the contributions to this volume based on Jensen's template model show. 
The psychological theorizing underlying the two ethics of Autonomy and Community has its roots in a long line of psychological research. Ryan and Deci (2000), for example, assume the driving quality of three basic needs: autonomy, relatedness, and competence. The need for autonomy has been assumed to be a driving force in most mainstream developmental and social psychological research. The relevance of relatedness (and belonging) was "discovered" in the psychology of religion (Bakan, 1966) and of gender and achievement (Spence, 1985), and later it was acknowledged in personality and developmental research (Guisinger \& Blatt, 1994). While autonomy has been considered a basic need in most research carried out in Western countries, the impact of relatedness and interdependence has been discussed in culture-informed social psychological and developmental research (e.g., Markus \& Kitayama, 1991).

The value of interdependence resembles Jensen's (2015) description of the Ethic of Community. The value of relatedness organizes moral thinking and behavior around the goals of taking care of the well-being of others (preferably group members such as one's family) and maintaining and fostering social harmony. When social-oriented values of relatedness organize morality, appropriate moral behavior requires emotional and behavioral self-regulation. For example, when frustration arises, anger expression is avoided or inhibited in order not to affect social harmony. Moreover, the experience of anger is less prevalent and occurs only later in development as a result of socialization conditions of anger inhibition (Kornadt, 2011). In Java and Japan, for example, the expression of anger is conceived of as immature and therefore is discouraged (Cole \& Tan, 2007; Trommsdorff, 2012b). Self-regulation in the expression of negative emotions is regarded as a "prosocial" moral value. From a European American cultural perspective, in contrast, self-regulation and inhibition of negative emotions and behavior are often seen as running counter to the value of authentic emotions and behaviors. The Ethic of Community, then, may serve individual needs for relatedness and the needs of group members to maintain group harmony. These needs could induce conflicting motivations and goals in cases of adhering to an independent self-construal. In cases of prioritizing cultural values of interdependence, such conflicting motivations are less probable (Trommsdorff, 2012b).

In culture-informed research, the notion of interdependence (often contrasted with independence) may capture the specific moral values characterizing the Ethic of Community. Some cultural-developmental studies acknowledge the coexistence of autonomy and relatedness (e.g., Kagitcibasi, 2005). However, studies focusing on the culture-specific meaning of autonomy and relatedness have shown cultures that prioritize interdependency as a normative cultural value in socialization to have a stronger preference for relatedness (Rothbaum \& Trommsdorff, 2007). The development of relatedness is based on emotional bonding and assurance (Rothbaum \& Trommsdorff, 2007). That said, 
relatedness in Asian cultures such as Japan also entails autonomy. For example, in our studies we have found that the Japanese mother allows her child to continue playing even though she wants her child to comply and go home. Her actively "giving in" (model for secondary control) induces empathic concern in her child and the motivation to actively restore harmony in the motherchild relation; accordingly, the child complies without frustration (secondary control; Trommsdorff \& Kornadt, 2003). Thus, the Ethic of Community may foster the development of interdependence, empathy, and prosocial behavior while individuals engage Autonomy to repair or to stabilize the interpersonal relationship. This dynamic co-occurrence of ethics that I have seen in Japan is in line with the suggestions by Hickman and DiBianca Fasoli (Chapter 7, this volume). Empirical data on the functional relation between autonomy and relatedness have also been gathered in a study on distress and prosocial behavior in German, Israeli, Indonesian, and Malaysian preschool children (Trommsdorff, Friedlmeier, \& Mayer, 2007). This study suggested that the Ethic of Community (prosocial behavior) can be inhibited by an imbalance in the value of autonomy and relatedness in preschool children. Further research should deal with questions of value change, the "successful" transmission of values during socialization (Trommsdorff, 2012a), and conditions for discrepancies in the preference of autonomy or community values and for possible parent-child conflict (in contrast with family relatedness) during development.

My colleagues and I have found that family relatedness (an aspect of the Ethic of Community) was closely associated with religiosity in a study of adolescents from eighteen countries (Mayer \& Trommsdorff, 2012). In this volume, Hickman and DiBianca Fasoli show how the moral reasoning of American evangelical parents legitimizes their child's Ethic of Autonomy reasoning while simultaneously recasting it into Ethic of Divinity concepts. In other cultural contexts, too, boundaries between secular and religious life are permeable (Snibbe \& Markus, 2002; Trommsdorff, 2012a). For example, in Indonesia, religion is experienced by Muslim adolescents as interwoven with collectivistic values (French, Eisenberg, Purwono, et al., 2012). Similarly, religion in India permeates everyday life and is intertwined with Hindu children's and adolescents' self-construals (Jensen, Chapter 1, this volume; Mishra, 2012; Pandya \& Bhangaokar, Chapter 2, this volume). The key Hindu moral concept of dharma is understood "as performing of duties pertaining to one's station in life" (Kapadia \& Bhangaokar, Chapter 4, this volume). The Hindu culture conceptualizes the self as a spiritual and an embodied entity interrelated with the divine, with nature, and with all living beings. This view does not make for an easy distinction of self's and others' interests in moral behavior, while values of interdependence and acceptance of rules in line with the Ethic of Divinity underlie agency in children's and adolescents' development (Mishra, 2012; Trommsdorff, 2012a). 
In turn, this may suggest that the meanings of the concepts of "autonomy" and "relatedness" may change when studied as aspects of the Ethic of Divinity instead of as aspects of the Ethics of Autonomy and Community. Accordingly, from a cultural-developmental approach these concepts and their impact on moral behavior should be studied from an indigenous perspective, for comparing the impact of the three ethics on moral behavior across cultures and developmental periods, their relative importance, and, moreover, the degree of their interrelations may induce a dynamic process-oriented approach to moral development.

When the development of morality is guided by religious normative beliefs (e.g., Ethic of Divinity), a closer look at the kind of religiosity in question is needed for predicting the kind of moral behavior (such as its relation to the Ethic of Community). Religious beliefs based on the sanctification of life can fundamentally transform the awareness of one's self and the world (Rothbaum \& Wang, 2012; Trommsdorff, 2012a). For example, the belief in sacred, unquestionable moral rules and values originating in "holy demands" may evoke a sharp contrast between believers and nonbelievers. Accordingly, moral behavior may entail cooperation with one's in-group members and opposition or even fighting against out-groups of nonbelievers. The Ethic of Divinity may be regarded as a legitimate basis for aggression against nonbelievers (Kornadt, 2012). Dynamic processes of commitment to one's in-group may increase the moral legitimacy of aggression and violence against the out-group (Trommsdorff, 2012a; in press). In a secular understanding, community values are understood as universalistic values (as human rights) that are not confined to an in-group of believers. However, secular worldviews can as well entail opposition to out-groups and activate "nonmoral" behavior such as aggression. This line of reasoning opens the door to question under which conditions the three general ethics can predict moral and immoral behavior.

While the general ethics (Divinity, Community, Autonomy) cannot alone predict moral behavior, more has to be known about their interrelations, the predominant cultural values, the individual self- and worldviews, and the specific context for moral agency. Co-occurrence of the Ethics of Divinity, Community, and Autonomy may be related to primary control (changing nonbelievers' beliefs) or to secondary control (changing oneself by self-regulation, suffering, undergoing hardships). Shweder, Much, Mahapatra, and Park (1997) have suggested a culture-informed view on the "big three explanations of suffering." In the Indian culture, suffering plays an important role in the Ethic of Divinity. Numerous rituals practiced individually and collectively permeate everyday life, with certain rituals inducing physical and psychological hardships (e.g., walking long distances without consuming water or food; walking over fire). However, enduring these ritual ordeals contributes to the participant's happiness (Fischer, Xygalatas, Mitkidis, et al., 2014). This process is related to 
secondary control (or changing the self) by extending one's self-regulation to accept extreme suffering.

A culture-informed approach allows us to better understand the impact of the Ethic of Divinity on moral behavior. The religious concepts promoted by Christianity in the European American contexts do not suffice, as is illustrated by the contributions of Pandya and Bhangaokar (Chapter 2, this volume) and by Kapadia and Bhangaokar (Chapter 4 , this volume), suggesting a merger of indigenous psychology and a cultural-developmental perspective. The latter authors, in fact, point out that the cross-cultural validity of the Three Ethics framework partly is due to the ethics' interrelations with self-construal and its components. This view is in line with my assumption that the development of moral reasoning and moral behavior is guided by one's self-construal influencing agency and self-regulation; the development of moral reasoning and moral behavior in cultural contexts is shaped by cultural values.

\section{Conclusion and outlook}

Future research is needed to study the culturally preferred modes of moral agency and its transmission into individual development and moral behavior. Assuming that individuals choose developmental contexts and behavioral options with optimal cultural fit, focus on the study of agency as part of moral development in cultural contexts is suggested. A cultural fit should enhance self-evaluation. In their cross-cultural study on the cultural value of self-esteem Becker, Vignoles, Owe, et al. (2014) showed that the basis of self-evaluations depends on cultural normative value priorities. The implication points out the need to pay more attention to value orientations and individual motivation in future research with the template model approach. For example, doing one's duty may be based on different motivations (e.g., promoting social approval and self-esteem; prevention of social rejection) that require choice and intentionality, thereby fostering agency. Conforming to prescribed moral behavior such as helping a person in need may be primarily motivated by empathic concern and less by perceived moral duty, depending on the meaning of the situation. Further research should distinguish emotion-based and duty-based agency for predicting moral behavior. Both kinds of agency may be activated in secular cultures prioritizing Ethics of Autonomy and Community and also in transcendent cultures prioritizing ethics of spirituality.

To recapitulate, Jensen's template model approach draws on Shweder and his colleagues' (1997) tripartite distinction among Ethics of Autonomy, Community, and Divinity to propose culturally malleable developmental patterns of moral reasoning. In future theoretical and empirical work, this culturaldevelopmental template model may be fruitfully extended by focusing on moral motivation and moral behavior and by building on theory of agency and the 
development of intentionality in cultural contexts. This cultural-developmental and motivational approach will gain from research on the development of selfand other-oriented worldviews contributing to the area of agentic moral development as a motivation to achieve fit between the self and the world in line with moral standards.

\section{REFERENCES}

Bakan, D. (1966). The duality of human existence: An essay on psychology and religion. Chicago, IL: Rand McNally.

Becker, M., Vignoles, V. L., Owe, E., Easterbrook, M. J., Brown, R., Smith, P. B., .. Koller, S. H. (2014). Cultural bases for self-evaluation: Seeing oneself positively in different cultural contexts. Personality and Social Psychology Bulletin, 40(5), 657-675. doi: $10.1177 / 0146167214522836$

Cole, P. M., \& Tan, P. Z. (2007). Emotion socialization from a cultural perspective. In J. E. Grusec \& P. Hastings (Eds.), Handbook of socialization: Theory and research (pp. 516-542). New York, NY: Guilford Press.

Dweck, C. S. (2000). Self-theories: Their role in motivation, personality, and development. Philadelphia, PA: Psychology Press.

Fischer, R., Xygalatas, D., Mitkidis, P., Reddish, P., Tok, P., Konvalinka, I., \& Bulbulia, J. (2014). The fire-walker's high: Affect and physiological responses in an extreme collective ritual. PLoS ONE, 9(2), e88355. doi:10.1371/journal.pone.0088355

French, D. C., Eisenberg, N., Purwono, U., \& Sallquist, J. A. (2012). Indonesian Muslim adolescents and the ecology of religion. In G. Trommsdorff \& X. Chen (Eds.), Values, religion, and culture in adolescent development (pp. 146-163). New York, NY: Cambridge University Press.

Grusec, J. E., \& Goodnow, J. J. (1994). Impact of parental discipline methods on the child's internalization of values: A reconceptualization of current points of view. Developmental Psychology, 30(1), 4-19. doi:10.1037/0012-1649.30.1.4

Guisinger, S., \& Blatt, S. J. (1994). Individuality and relatedness: Evolution of a fundamental dialectic. American Psychologist, 49(2), 104-111. doi:10.1037/0003066X.49.2.104

Heikamp, T., Trommsdorff, G., \& Fäsche, A. (2013). Development of self-regulation in context. In G. Seebaß, M. Schmitz, \& P. M. Gollwitzer (Eds.), Acting intentionally and its limits: Individuals, groups, institutions (pp. 193-222). Berlin, Germany: De Gruyter.

Higgins, E. T. (2012). Beyond pleasure and pain. Oxford, United Kingdom: Oxford University Press.

Jensen, L. A. (2008). Through two lenses: A cultural-developmental approach to moral psychology. Developmental Review, 28(3), 289-315. doi:http://dx.doi.org/ 10.1016/j.dr.2007.11.001

(2011). The cultural-developmental theory of moral psychology: A new synthesis. In L. A. Jensen (Ed.), Bridging cultural and developmental approaches to psychology: New syntheses in theory, research, and policy (pp. 3-25). New York, NY: Oxford University Press.

(Ed.). (2015). The Oxford handbook of human culture and development: An interdisciplinary approach. New York, NY: Cambridge University Press. 
Kagitcibasi, C. (2005). Autonomy and relatedness in cultural context: Implications for self and family. Journal of Cross-Cultural Psychology, 36(4), 403-422. doi:10.1177/0022022105275959

Karoly, P. (1993). Mechanisms of self-regulation: A systems view. Annual Review of Psychology, 44(1), 23-52. doi:10.1146/annurev.ps.44.020193.000323

Kochanska, G., Coy, K. C., \& Murray, K. T. (2001). The development of selfregulation in the first four years of life. Child Development, 72(4), 1091-1111. doi:10.1111/1467-8624.00336

Kornadt, H.-J. (2011). Aggression: Die Rolle der Erziehung in Europa und Ostasien [Aggression: The role of socialization in Europe and East Asia]. Wiesbaden, Germany: VS Verlag.

(2012). Psychological functions of religion in youth: A historical and cultural perspective. In G. Trommsdorff \& X. Chen (Eds.), Values, religion, and culture in adolescent development (pp. 46-65). New York, NY: Cambridge University Press.

Markus, H. R., \& Kitayama, S. (1991). Culture and the self: Implications for cognition, emotion, and motivation. Psychological Review, 98(2), 224-253. doi:10.1037/0033-295X.98.2.224

Mayer, B., \& Trommsdorff, G. (2012). Cross-cultural perspectives on adolescents' religiosity and family orientation. In G. Trommsdorff \& X. Chen (Eds.), Values, religion, and culture in adolescent development (pp. 341-369). New York, NY: Cambridge University Press.

Miller, J. G., Bersoff, D. M., \& Harwood, R. L. (1990). Perceptions of social responsibilities in India and in the United States: Moral imperatives or personal decisions? Journal of Personality and Social Psychology, 58(1), 33-47. doi:10.1037/00223514.58.1.33

Mischel, W. (1996). From good intentions to willpower. In P. M. Gollwitzer \& J. A. Bargh (Eds.), The psychology of action: Linking cognition and motivation to behavior (pp. 197-218). New York, NY: Guilford Press.

Mishra, R. C. (2012). Hindu religious values and their influence on youths in India. In G. Trommsdorff \& X. Chen (Eds.), Values, religion, and culture in adolescent development (pp. 424-442). New York, NY: Cambridge University Press.

Molden, D. C., \& Dweck, C. S. (2006). Finding "meaning" in psychology: A lay theories approach to self-regulation, social perception, and social development. American Psychologist 61(3), 192-203. doi:10.1037/0003-066X.61.3.192

Morling, B., \& Evered, S. (2006). Secondary control reviewed and defined. Psychological Bulletin, 132, 269-296. doi:10.1037/0033-2909.132.2.269

Rothbaum, F., \& Trommsdorff, G. (2007). Do roots and wings oppose or complement one another? The socialization of autonomy and relatedness in cultural context. In J. E. Grusec \& P. Hastings (Eds.), The handbook of socialization (pp. 461-489). New York, NY: Guilford Press.

Rothbaum, F., \& Wang, Y.Z. (2011). Cultural and developmental pathways to acceptance or self and acceptance of the world. In L. A. Jensen (Ed.), Bridging cultural and developmental approaches to psychology: New syntheses in theory, research, and policy (pp. 187-211). New York, NY: Oxford University Press.

Rothbaum, F., \& Wang, Y. Z. (2012). Fostering the child's malleable views of the self and the world: Caregiving practices in East Asian and European-American communities. In B. Mayer \& H.-J. Kornadt (Eds.), Psychologie Kultur Gesellschaft (Psychology - Culture - Society) (pp. 101-20). Wiesbaden, Germany: VS Verlag für Sozialwissenschaften. 
Ryan, R. M., \& Deci, E. L. (2000). Self-determination theory and the facilitation of intrinsic motivation, social development, and well-being. American Psychologist, 55(1), 68-78. doi:10.1037/0003-066X.55.1.68

Shweder, R. A. (1990). In defense of moral realism: Reply to Gabennesch. Child Development, 61(6), 2060-2067. doi:10.2307/1130859

Shweder, R. A., Much, N. C., Mahapatra, M., \& Park, L. (1997). The "Big Three" of morality (Autonomy, Community, Divinity) and the "big three" explanations of suffering. In A. M. Brandt \& P. Rozin (Eds.), Morality and health (pp. 119-169). New York, NY: Routledge.

Snibbe, A. C., \& Markus, H. R. (2002). The psychology of religion and the religion of psychology. Psychological Inquiry, 13(3), 229-234.

Spence, J. T. (1985). Achievement American style: The rewards and costs of individualism. American Psychologist, 40, 1285-1295. doi:10.1037/0003-066X.40.12.1285

Tomasello, M. (1999). Having intentions, understanding intentions, and understanding communicative intentions. In P. D. Zelazo, J. W. Astington, \& D. R. Olson (Eds.), Developing theories of intention: Social understanding and self-control (pp. 6375). Mahwah, NJ: Erlbaum.

Trommsdorff, G. (2007). Intentionality of action in cultural context. In J. Wassmann \& K. Stockhaus (Eds.), Person, space and memory in the contemporary PacificExperiencing New Worlds: Vol. 1. Person, space and memory - Theoretical foundations (pp. 58-77). New York, NY: Berghahn.

(2009). Culture and development of self-regulation. Social and Personality Psychology Compass, 3(5), 687-701. doi:10.1111/j.1751-9004.2009.00209.x

(2012a). Cultural perspectives on values and religion in adolescent development: A conceptual overview and synthesis. In G. Trommsdorff \& X. Chen (Eds.), Values, religion, and culture in adolescent development (pp. 3-45). Cambridge, NY: Cambridge University Press.

(2012b). Development of 'agentic' regulation in cultural context: The role of self and world views. Child Development Perspectives, 6(1), 19-26. doi:10.1111/j.17508606.2011.00224.x

(2015). Cultural roots of values, and moral and religious purposes in adolescent development. In L. A. Jensen (Ed.), The Oxford handbook of human culture and development: An interdisciplinary approach. New York, NY: Oxford University Press.

(in press). Entwicklung von Intentionalität: Implikationen für moralische Entwicklung im kulturellen Kontext. In J. Sautermeister (Ed.), Moralpsychologie: Transdisziplinäre Perspektiven. Stuttgart, Germany: Kohlhammer.

Trommsdorff, G., Friedlmeier, W., \& Mayer, B. (2007). Sympathy, distress, and prosocial behavior of preschool children in four cultures. International Journal of Behavioral Development, 31(3), 284-293. doi:10.1177/0165025407076441

Trommsdorff, G., \& Kornadt, H.-J. (2003). Parent-child relations in cross-cultural perspective. In L. Kuczynski (Ed.), Handbook of dynamics in parent-child relations (pp. 271-304). London, United Kingdom: Sage.

Weisz, J. R., Rothbaum, F. M., \& Blackburn, T. C. (1984). Standing out and standing in: The psychology of control in America and Japan. American Psychologist, 39, 955-969. doi:10.1037/0003-066X.39.9.955 